\title{
Control of Metal Coordination Number in De Novo Designed Peptides Through Subtle Sequence Modifications
}

\author{
Kyung-Hoon Lee, Manolis Matzapetakis, Soumya Mitra, E. Neil G. Marsh and \\ Vincent L. Pecoraro* \\ Department of Chemistry, University of Michigan \\ Ann Arbor, Michigan 48109-1055.
}

\section{SUPPORTING INFORMATION}

Figure S1. UV-VIS titration of TRI L12A/L16C into a solution of $\mathrm{Cd}(\mathrm{II})$ at $\mathrm{pH}$ 8.5. The data are plotted as $\Delta \varepsilon$ vs. wavelength. The inset to the figure provides the titration curve plotted as $\Delta \varepsilon$ at $231 \mathrm{~nm}$ vs equivalents of peptide added. The $[\mathrm{Cd}(\mathrm{II})]=20 \mu \mathrm{M}$.

Figure S2. Portion of the NOESY spectrum of Cd(TRI L12V/L16C) ${ }_{3}{ }^{-}$showing the amide region of the peptide. We observed and assigned 22 separate amide resonances indicating that the peptide coiled coil exists in the parallel conformation. The spectrum was collected on a Bruker AMX500 NMR using the provided pulse sequence "noesyprsh" on a $5 \mathrm{mM}$ sample in a $10 \% \mathrm{D}_{2} \mathrm{O}$ solution at $\mathrm{pH} 8.5$ with no buffer. A presaturation pulse of $1.5 \mathrm{sec}$ was applied to eliminate the water signal and a $100 \mathrm{~ms}$ mixing time delay was used. The assignment was possible using the $i+1$ and $i-1$ NOESY peaks between the amide protons of the $\alpha$-helix. 
Figure S1

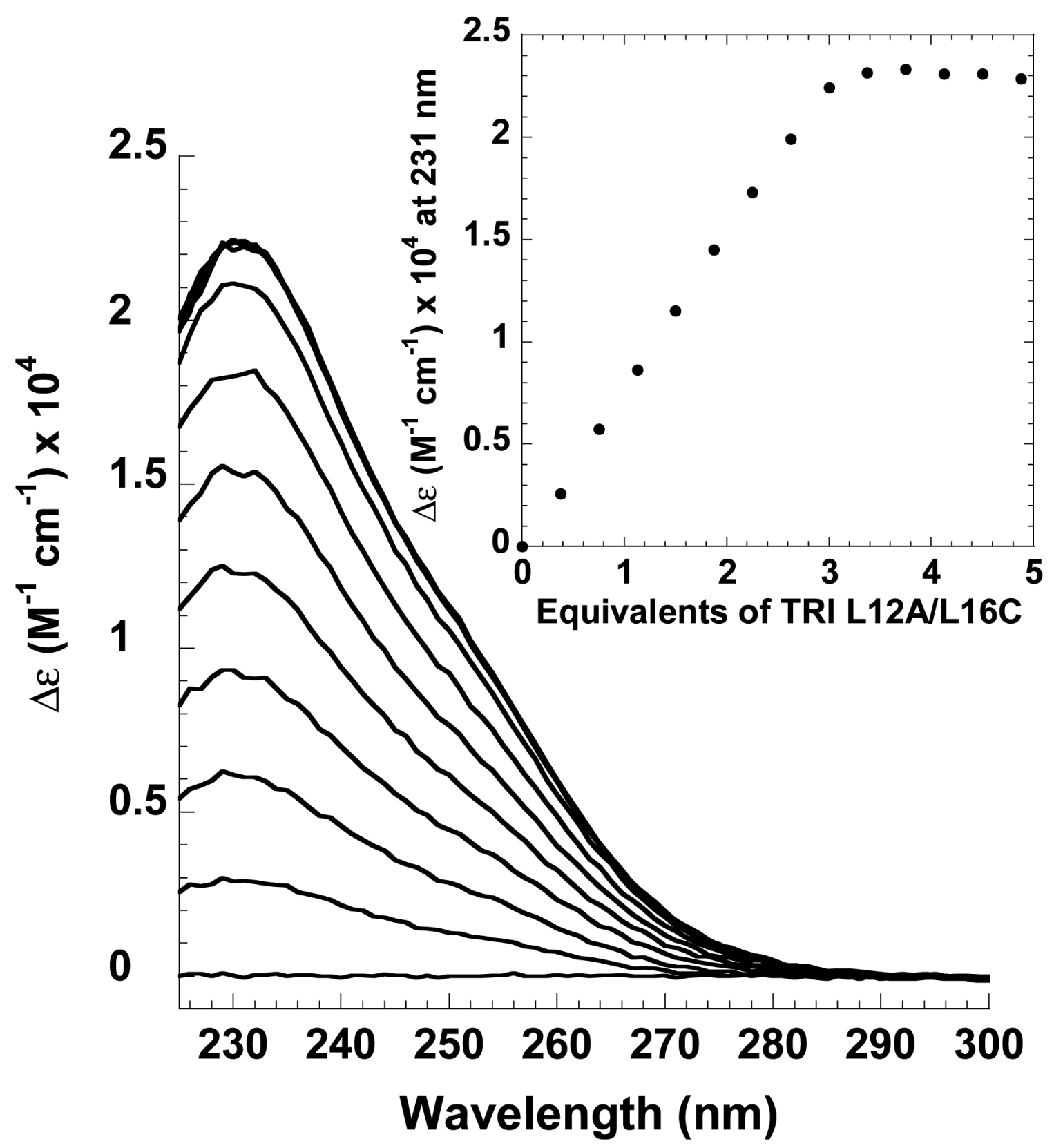


Figure S2

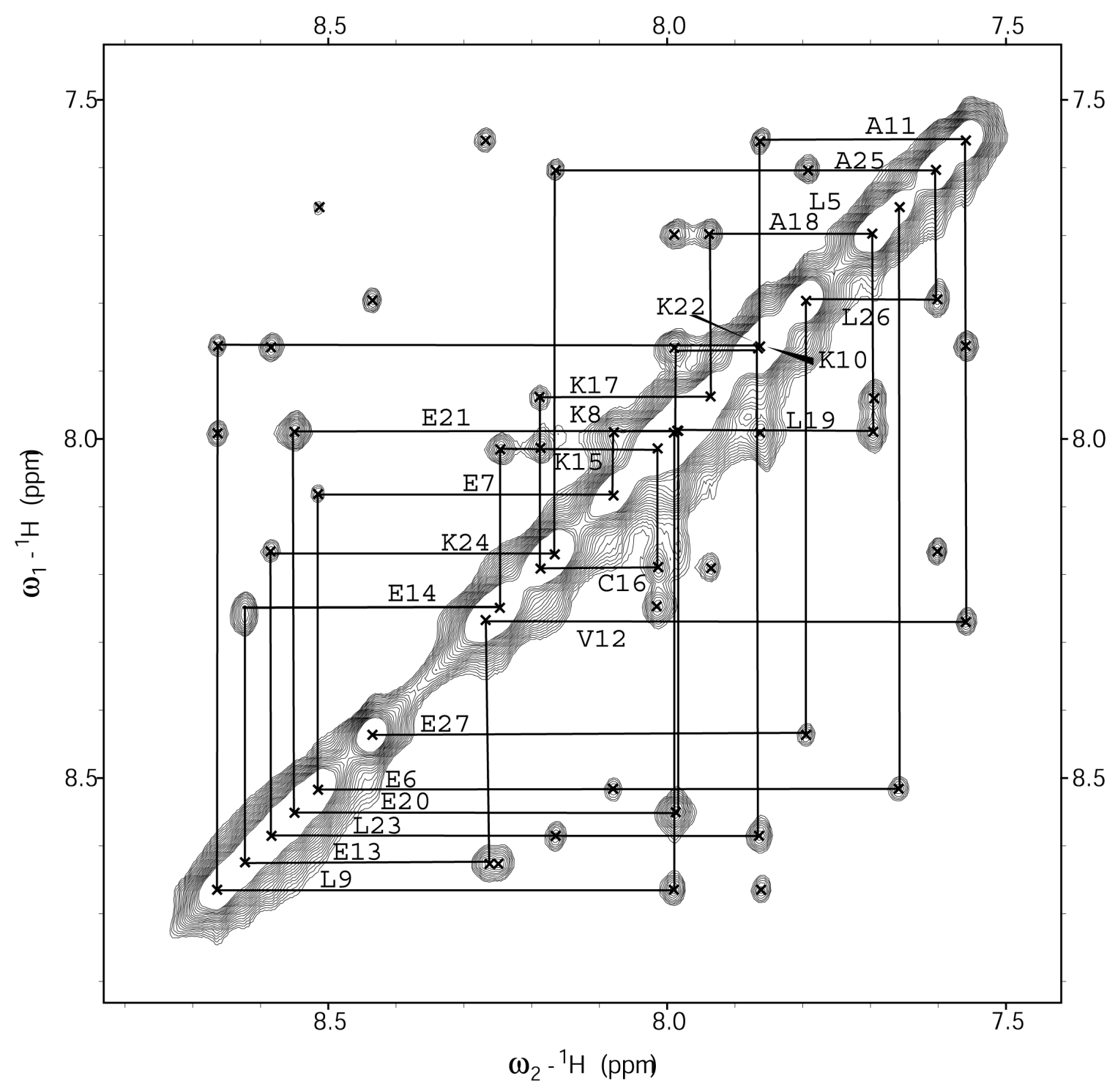

